\title{
ATIVIDADE DA GAMA GLUTAMIL TRANSPEPTIDASE URINÁRIA, DOSAGENS SÉRICAS DE URÉIA E CREATININA COMO MEIOS DIAGNÓSTICOS AUXILIARES NA NEFROTOXICIDADE INDUZIDA POR AMINOGLICOSÍDEO EM CÃES ${ }^{1}$
}

\author{
URINARY GAMMA GLUTAMYL TRANSPEPTIDASE ACTIVITY, URINALYSIS, BUN AND \\ CREATININE SERUM DOSAGES AS A AUXILIARY DIAGNOSTIC MEAN IN \\ DOGS NEPHROTOXICITY INDUCED BY AMINOGLYCOSIDES
}

\author{
Carla Rosane de Aguiar Hennemann ${ }^{2}$ Cândido Fontoura da Silva ${ }^{3}$ Willian Schoenau ${ }^{4}$ \\ Glaucia Denise Kommers ${ }^{5}$ Alexandre da Silva Polydoro ${ }^{6}$ \\ Marcus Roberto Mielke Leitzke ${ }^{7}$
}

RESUMO

Foram utilizados 11 cães, hígidos, com idade entre 1 e 5 anos. Inicialmente procedeu-se à determinação dos valores basais através de cinco colheitas diárias de urina e sangue, e realizou-se a urinálise, determinação da atividade da gama glutamil transpeptidase urinária, dosagens sérica de uréia e creatinina. A nefrotoxicidade foi induzida com a utilização de $10 \mathrm{mg} / \mathrm{kg}$ de gentamicina, 3 vezes ao dia, durante 14 dias. As colheitas de urina foram realizadas a cada 24 hors e o sangue foi colhido a cada 48 horas, durante 14 dias. Após este período os cães foram submetidos à eutanásia, procedendo-se à necropsia, e estudo histopatológico dos rins. Os sinais clínicos apresentados foram apatia, anorexia, poliúria, oligúria, anúria, polidipsia, vômito e diarréia. Pela urinálise observou-se a ocorrência de proteinúria, glicosúria, hematúria, cilindrúria, celulúria e isostenúria; os valores de gama glutamil transpeptidase urinária elevaram-se de forma crescente a partir de 24 horas de administração da gentamicina até o final do experimento, a azotemia foi observada no $12^{\circ}$ e $14^{\circ}$ dias da pesquisa. $\mathrm{Na}$ avaliação histopatológica observou-se nefrose tubular aguda. Com base nos resultados obtidos pode-se concluir que a mensuração da atividade da gama glutamil transpeptidase urinária é um sensível indicador de lesão tubular renal possibilitando o diagnóstico precoce, juntamente com a urinálise.

Palavras-chave: nefrotoxicidade, gama glutamil transpeptidase urinária, cães.

${ }^{1}$ Parte da dissertação de mestrado apresentada pelo primeiro autor ao Curso de Pós-graduação em medicina Veterinária da Universidade Federal de Santa Maria (UFSM), Santa Maria, RS.

${ }^{2}$ Médico Veterinário, Mestre, Professor do Departamento de Medicina Veterinária da Universidade Luterana do Brasil - ULBRA e Professor Substituto UFRGS. Rua Pe. Anchieta 66/301, 92110-050 - Canoas, RS. Autor para correspondência.

${ }^{3}$ Médico Veterinário, Mestre, Professor Adjunto, Departamento de Clínica de Pequenos Animais, UFSM.

${ }^{4}$ Médico Veterinário, Mestre, Professor Assistente, Departamento de Fisiologia, UFSM.

${ }^{5}$ Médico Veterinário, Mestre, Professor Assistente, Departamento de Patologia, UFSM.

${ }^{6}$ Médico Veterinário, Mestre, Professor do Departamento de Medicina Veterinária da Universidade Luterana do Brasil - ULBRA.

${ }^{7}$ Acadêmico de Medicina Veterinária, bolsista - PRAE/UFSM. 


\section{SUMMARY}

Eleven healthy dogs, ranging from one to five years old, were used for this study. Base line values were determined through five daily samples of urine for urinalysis and urinary gamma glutamyl transpeptidase activity, and blood for serum dosage of BUN and creatinine. Nephrotoxicity was induced using 10mg/kg of gentamicin, 3 times a day (tid), for 14 days. Urine samples were drawn every 24 hours and blood samples every 48 hours, for 14 days. After this period, the dogs were euthanized and necropsy was done for further histopathologic study. The clinical signs shown by the dogs were lethargy, anorexy, polyuria, oliguria, anuria, polydypsia, vomiting and diarrhea. Urinalysis findings were proteinuria, glucosuria, hematuria, cilindruria, celluria and decrease of urinary specific gravity and crescent values of urinary gamma glutamyl transpeptidase from 24 hours after gentamicin administration until the "end of" the experiment. Azotemia was noticed on the $12^{\text {th }}$ and $14^{\text {th }}$ days of the study. Acute tubular nephrosis was established in the histological evaluation. Based on the results found on this study, the measurement of the urinary gamma glutamyl transpeptidase activity might be considered a sensitive indicator of renal tubular damage allowing early diagnosis of the lesion.

Key words: nephrotoxicity, urinary gamma glutamyl transpeptidase, dogs.

\section{INTRODUÇÃO}

A insuficiência renal aguda associada a gentamicina tem sido reportada em cães, gatos e cavalos (BROWN et al., 1985; HARDY et al., 1985; BROWN et al., 1986). A administração de gentamicina, um antibiótico aminoglicosídeo utilizado em infecções por bactérias gram-negativas, tem sido limitado pelo seu potencial de nefrotoxicidade e ototoxicidade (GRECO et al., 1985; HARDY et al., 1985; BARSANTI, 1988).

GRAUER (1989) destacou que os insultos tóxicos aos rins são freqüentemente causados por agentes terapêuticos e que a gentamicina é considerada a causa mais comum de insuficiência renal aguda tóxica. De acordo com POLZIN et al. (1992) o córtex renal é especialmente vulnerável a ação dos agentes tóxicos porque recebe $90 \%$ do fluxo sangüíneo renal e a superfície endotelial dos capilares glomerulares é considerada bastante grande.

Muitos investigadores têm defendido o uso de um programa de monitorização para detecção precoce da nefrotoxicidade induzida por gentamicina e como prevenção na progressão da insuficiência renal através da interrupção da terapia com aminoglicosídeo (BROWN et al., 1985). Para BROWN et al. (1985), GRECO et al. (1985), BAYLY et al. (1986) e BARSANTI (1988) a urinálise seriada é o método mais efetivo e sensível na detecção de nefrotoxicidade por gentamicina, e possibilita a detecção de toxicidade antes da elevação da concentração sérica da uréia e de creatinina. Mas esses autores são unânimes em afirmar que em alguns casos os achados referentes a urinálise foram inconscistentes.

As enzimas urinárias são citadas por STROO \& HOOK (1977), PRICE (1982), BRAUN et al. (1983), HARDY et al. (1985), BRAUN et al. (1987), GROSSET et al. (1987) e FINCO (1989), como um sensível indicador de lesão renal e embora tenham sido estudadas uma ampla variedade de enzimas, poucas têm se destacado na prática clínica. As enzimas urinárias têm sido utilizadas em estudos de nefrotoxicidade, já que a variação no estado clínico é observado mais tardiamente.

A gama glutamil transpeptidase tem sua concentração máxima nos bordos em escova dos túbulos renais proximais e alça de Henle. Esta enzima exerce papel essencial no transporte de aminoácidos e participa na manutenção da reserva de aminoácidos na célula. Também são encontradas pequenas concentrações em outros órgãos: fígado, pâncreas, baço, pulmão, intestino delgado, placenta, sistema nervoso central, próstata e miocárdio (SHAW, 1976; SALGÓ \& SZABÓ, 1982; RUDOLPH \& CORVALAN, 1992).

DE SCHEPPER $\boldsymbol{e t}$ al. (1989), afirmaram que a variação na atividade das enzimas urinárias entre uma única amostra de urina da manhã e outra 18 horas mais tarde, está relacionada com a densidade urinária das duas amostras. Frente a este fato utilizou a densidade de 1025 como fator de correção para o fluxo urinário de uma única amostra coletada de cada animal, através da seguinte fórmula:

$$
\mathrm{X}=\frac{\mathrm{Yx} 25}{\mathrm{Z}}
$$

Onde: $\mathrm{X}=$ Concentração de gama glutamil transpeptidase urinária calculada; $Y=$ Concentração de gama glutamil transpeptidase urinária da amostra; $\mathrm{Z}=$ Últimos dois dígitos da densidade urinária da amostra.

DE SCHEPPER et al. (1989) paralelamente ao trabalho acima citado, determinaram os valores basais para gama glutamil transpeptidase urinária corrigidos pela fórmula de ajuste, sendo estes 13 a 92U/I.

SHAW (1976) e GARRY et al. (1990) trabalhando com ovinos, BAYLY et al. (1986) com pôneis, HARDY et al. (1985) com felinos, GRECO et al. (1985), OGURA (1986), DE SCHEPPER $\boldsymbol{e}$ t al. (1989) e HEIENE et al. (1991) com caninos, avaliaram a nefrotoxicidade tóxica através da mensuração da atividade da gama glutamil transpeptidase urinária. 
Esta apresentou sua atividade aumentada precocemente, ou seja, antes das alterações na urinálise, uréia e creatinina.

Historicamente, a uréia e creatinina sérica têm sido utilizadas como índice de retenção dos compostos nitrogenados não protéicos eliminados pelos rins. Portanto, as concentrações de uréia e creatinina sérica são inversamente proporcionais à taxa de filtração glomerular (COLES, 1984; OSBORNE \& POLZIN, 1983; FINCO, 1989; CHEW \& DIBARTOLA, 1992; WILLARD et al., 1994; MEYER et al., 1995.

Sendo uma das características dos rins sua capacidade compensatória ao prejuízo, observam-se danos funcionais somente quando houver perda de 3/4 da capacidade funcional dos néfrons de ambos os rins. Em razão destas características fisiológicas dos rins, e da necessidade de novos testes renais mais específicos visando o diagnóstico precoce da lesão renal desenvolveu-se este estudo. Os objetivos principais foram o diagnóstico precoce e específico de lesão renal, através da avaliação da atividade da enzima urinária gama glutamil transpeptidase frente a nefrotoxicidade induzida com gentamicina, bem como a realização dos testes de função renal convencionais, tais como urinálise, dosagens sérica de uréia e creatinina.

\section{MATERIAIS E MÉTODOS}

O experimento foi realizado no setor de Clínica Médica e no Laboratório de Patologia Clínica do Hospital de Clínicas Veterinária da Universidade Federal de Santa Maria, RS.

Foram utilizados 11 cães, hígidos, sem raça definida, idade entre 1 e 5 anos sendo 4 machos e 7 fêmeas e com peso médio de $10,44 \pm 4,68 \mathrm{~kg}$, provenientes do Biotério Central da Universidade Federal de Santa Maria.

Previamente ao experimento os cães foram submetidos a exames clínico e laboratorial seletivos que constaram de hemograma, urinálise, determinação da atividade da gama glutamil transpeptidase urinária e dosagem sérica de uréia e creatinina. Permaneceram por um período de adaptação de 15 dias alojados em boxes individuais para ambientação e preparação para a fase experimental. Nesta fase os cães foram pesados, numerados aleatoriamente de 1 a 11 , desverminados e condicionados a realizar micção espontânea em períodos pré-determinados, duas vezes ao dia.

Foram realizadas cinco colheitas diárias de urina e sangue para realização da urinálise, determinação da atividade da gama glutamil transpeptidase urinária e dosagem sérica de uréia e creatinina. Os valores basais obtidos foram transformados em médias e utilizados como parâmetro de normalidade.

A nefrotoxicidade foi induzida com a utilização de aminoglicosídeo, gentamicina ${ }^{a}$, por via intramuscular na dose de $10 \mathrm{mg} / \mathrm{kg}$ (GRECO et al., 1985; OGURA, 1986; BEHREND et al, 1994) três vezes ao dia durante 14 dias.

Para avaliação da função renal foram realizados urinálise, determinação da atividade da gama glutamil transpeptidase urinária, dosagens séricas de uréia e creatinina.

As amostras de urina foram colhidas através de micção espontânea, a cada 24 horas e processadas imediatamente. $\mathrm{O}$ sangue foi colhido a cada 48 horas para a determinação da concentração de uréia e creatinina pelo método colorimétrico utilizando-se "kits comerciais"b e espectrofotômetro Spectronic 21".

A determinação da atividade da enzima urinária gama glutamil transpeptidase foi realizada com o sobrenadante urinário utilizando-se "kit comercial"d e espectrofotômetro SB $215 \mathrm{P}^{\mathrm{e}}$. O valor da gama glutamil trranspeptidase urinária foi calculado através da equação citada por DE SCHEPPER et al., (1989).

Também foram avaliados os sinais clínicos durante todo o período de experimentação.

Os animais foram submetidos à eutanásia, sob anestesia geral por barbituratos, seguida do uso de agente bloqueador neuromuscular, procedendo-se a necropsia com posterior estudo histopatológico.

Os valores dos parâmetros coletados foram transformados em médias e submetidos a análise de variância e teste F. As médias foram comparadas sempre com o valor basal (DO) através do teste de contraste. Os achados referentes à urinálise sofreram uma conversão para dados de graduação a fim de que a estatística fosse aplicada, de acordo com FONTES et al. (1980).

\section{RESULTADOS}

\section{Avaliação clínica}

Observou-se manifestação de dor à aplicação da gentamicina, com exceção dos cães de números 2 e $6(18,18 \%)$. Apatia e anorexia progressiva pôde ser observada em todos os cães. Poliúria e polidipsia foram observadas em torno do $7^{\circ}$ ao $12^{\circ}$ dias, sendo que nos cães de números 1,2,4 e 6 (36,36\%) foram precedidos por oligúria. Os cães de números 7 e $10(18,18 \%)$ apresentaram poliúria e polidipsia a partir do $7^{\circ}$ e $9^{\circ}$ dias do experimento, com subseqüente 
oligúria e manifestação de sinais clínicos de vômito e diarréia; o cão de número 7 foi submetido a eutanásia no $12^{\circ}$ dia de experimentação pelo agravamento dos sinais clínicos. O cão de número 9 manifestou anúria por 72 horas e a posteriori, sinais como vômito, diarréia, incoordenação motora, mioclonias, hiperexcitabilidade e convulsões sendo submetido a eutanásia no $15^{\circ}$ dia do experimento.

\section{Avaliação laboratorial}

\section{Urinálise}

Os valores referentes a densidade urinária (Tabela 1) evidenciaram diferença estatisticamente significativa a partir do $6^{\circ}$ dia de colheita, observandose que esses valores decresciam de forma contínua até o $14^{\circ}$ dia de colheita, momento em que seis cães apresentavam-se em isostenúria.

No exame químico as proteínas demonstraram variação desde sua ausência até $? 500 \mathrm{mg} / \mathrm{dl}$ já na fase final do experimento. Glicosúria foi observada em seis cães, a partir do $9^{\circ}$ dia de colheita. O sangue oculto também foi um achado na prova química, quando no $14^{\circ}$ dia de colheita obteve-se $10 \%$ dos cães com $1 \mathrm{mg} /$ $\mathrm{dl}, 30 \%$ com $0,2 \mathrm{mg} / \mathrm{dl}$ e $60 \%$ negativos. Os valores de $\mathrm{pH}$ permaneceram entre 5,0 e 7,0 durante toda a fase de experimentação, e do mesmo modo os parâmetros de bilirrubina direta e urobilinogênio

Tabela I Valores medios, desvios padrờes e análise estatistica para as determinaçóex da densidade urinária e gama glutamil transpeptidase urinária de caes submetidos a nefrotoxicidade indazida por amineglicosideo. Santa Maria, 1996

\begin{tabular}{|c|c|c|c|c|}
\hline $\begin{array}{l}\text { Dias de } \\
\text { colheita }\end{array}$ & $\begin{array}{l}\text { Densidade Urinária } \\
\text { (Mćdia'desvio padalo) }\end{array}$ & Valor F & $\begin{array}{l}\text { Gama glutamil } \\
\text { Iranspeptidase(U/1) }\end{array}$ & Valor F \\
\hline D0 & $1059+09,38$ & & $21,50 \pm 04,11$ & \\
\hline DI & $1035=10.25$ & 1,09 & $52,14 \pm 22,69$ & 1,86 \\
\hline D2 & $1039 \pm 09.25$ & 0,01 & $57,92+28,60$ & 2,50 \\
\hline D3 & $1038 \pm 08.41$ & 0,04 & $80,12+49,92$ & $6.82^{\circ}$ \\
\hline D4 & $1033=09.13$ & 2.36 & $90,27+49,87$ & $8,92^{* *}$ \\
\hline Ds & $1035 \pm 08.97$ & 0,72 & $78,29 \pm 41,23$ & $6,40^{+}$ \\
\hline 126 & $1029 \pm 08.80$ & $7.30^{* *}$ & $96,76 \pm 74,33$ & $11.25^{\circ}$ \\
\hline D7 & $1030=07,98$ & $5.54^{* *}$ & $104,13 \div 57,44$ & $13,56^{\circ}$ \\
\hline D8 & $1026 \div 07.35$ & $11,49^{\circ}$ & $90,06 \pm 39,33$ & $9,33^{* *}$ \\
\hline D9 & $1022+07,38$ & $20.58^{* *}$ & $104,44 \div 55,24$ & $14.28^{\circ-}$ \\
\hline D10 & $1023 \div 10,04$ & $17.86^{\circ}$ & $129,87 \times 61,67$ & $23,32^{\prime *}$ \\
\hline D11 & $1023 \div 06.78$ & $17.52^{\circ}$ & $133,61+52,48$ & $23,71^{* *}$ \\
\hline $\mathrm{D} 12$ & $1018 \pm 06,90$ & $30.87^{\circ *}$ & $127,10 \div 22,75$ & $18,41^{* 4}$ \\
\hline D13 & $1017+06.00$ & $32,19^{* *}$ & $150,62+33,79$ & $27,52^{\circ}$ \\
\hline DIA & 1013207,38 & $48,67^{*}$ & $213,83 \pm 85,90$ & $49,85^{\circ}$ \\
\hline
\end{tabular}

$\mathrm{P} \subset 0.01^{*+} \mathrm{P} \subset 0,05^{*}$ mantiveram-se normais, e corpos cetônicos negativo. No exame microscópico do sedimento urinário notou-se a presença de cilindros granulosos a partir do $7^{\circ}$ dia de colheita, sendo que sua frequiência absoluta mostrou-se crescente no decorrer do experimento. As células epiteliais descamativas derivadas da uretra, bexiga e vagina foram evidenciadas em número não significativo, enquanto as células epiteliais tubulares renais apresentaramse com um número crescente no decorrer do experimento. Quanto aos leucócitos e hemácias, observou-se aumento discreto na fase final do experimento, o mesmo acontecendo com a bacteriúria.

Cristais de fosfato e urato amorfo, fosfato triplo, filamento de muco e gotículas de gordura também foram encontrados. Espermatozóides estiveram presentes em diferentes porcentagens das amostras durante todo o experimento.

\section{Enzima urinária - gama glutamil transpeptidase}

Em relação aos valores da enzima urinária gama glutamil transpeptidase, listados na Tabela 1 , apresentaram diferença estatisticamente significativa a partir do $3^{\circ}$ dia de colheita, sendo que esses valores elevaram-se de forma crescente até o final do experimento.

\section{Uréia e Creatinina sérica}

Os valores médios para as dosagens sérica de uréia obtidos nos tempos estudados aprsentaram elevações com o andamento da pesquisa, atingindo o valor médio máximo $(85,40 \pm 80,73 \mathrm{mg} /$ dl) no $14^{\circ}$ dia do experimento, sendo este estatisticamente significativo (Tabela 2).

Os resultados obtidos para as dosagens de creatinina sérica demonstraram diferença estatisticamente signi-ficativa no $12^{\circ}$ e $14^{\circ}$ dias da observação, com valores médios de $2,18 \pm 1,41 \mathrm{mg} / \mathrm{dl}, \quad 5,86 \pm 5,35 \mathrm{mg} / \mathrm{d}$ respectivamente. Estes e os demais valores da creatinina sérica estão apresentados na Tabela 2 .

\section{Avaliação histopatológica}

Dentre os resultados re-ferentes ao exame histopatológico observou-se basicamente nefrose tubular aguda difusa ou segmentar, variando de discreta a acentuada, associada a cilindros granulosos e hialinos nos túbulos renais ou com grau variado de regeneração 
Tabela 2 - Valores médios, desvios padróes $\mathrm{e}$ andílise estatistica para as dosagens séricas de uréia e creatinina de càes submetidos a nefrotoxicidade induzida por aminoglicosideo. Santa Maria, 1996.

\begin{tabular}{|c|c|c|c|c|}
\hline DIAS DE COLHEITA & Uréia(mg/dl) & Valor $F$ & $\begin{array}{c}\text { Creatinina } \\
\text { (mg/dl) }\end{array}$ & Valor $\mathrm{F}$ \\
\hline \multirow[t]{2}{*}{ D0 } & 24,30 & & 0.67 & \\
\hline & $\pm 6,33$ & 000 & $\pm 0,13$ & 084 \\
\hline D2 & $\pm 5,70$ & & $\begin{array}{l}0,80 \\
0,18\end{array}$ & 0,84 \\
\hline \multirow[t]{2}{*}{ D4 } & 23,48 & 0,00 & 0,81 & 0,86 \\
\hline & $\pm 5,00$ & & $\pm 0,16$ & \\
\hline \multirow[t]{2}{*}{ D6 } & 25,51 & 0,02 & 0,87 & 0,97 \\
\hline & $\pm 5,82$ & & $\pm 0,19$ & \\
\hline \multirow[t]{2}{*}{ D8 } & 23.44 & 0,00 & 0,95 & 1,24 \\
\hline & $+4,89$ & & \pm 0.23 & \\
\hline \multirow[t]{2}{*}{ D10 } & 26,27 & 0,06 & 1.29 & 2,03 \\
\hline & $\pm 5,42$ & & $+0,44$ & \\
\hline \multirow[t]{2}{*}{ D12 } & 45,13 & 2,44 & 2,18 & $5.14^{\circ}$ \\
\hline & $+36,01$ & & $\pm 1,41$ & \\
\hline \multirow[t]{2}{*}{ D14 } & 85,40 & $20,64^{*}$ & 5,86 & $29.16^{\circ}$ \\
\hline & $\pm 80,73$ & & $+5,35$ & \\
\hline
\end{tabular}

$\mathrm{P}<0,01^{*} \mathrm{P}<0,05^{*}$

tubular.

\section{DISCUSSÃO}

A nefrotoxicidade foi induzida com $10 \mathrm{mg} /$ $\mathrm{kg}$ de gentamicina, 3 vezes ao dia, por via intramuscular. Doses e freqüência de administração semelhantes foram utilizadas por GRECO et al. (1985) e OGURA (1986) na indução de nefrotoxicidade experimental. BEHREND et al. (1994) também utilizaram esta mesma dosagem em um trabalho em que avaliou o efeito da proteína na dieta sobre a farmacocinética da gentamicina em cães com função renal normal.

Os sinais clínicos apresentados pelos cães foram semelhantes aos referenciados por GRECO et al. (1985). A poliúria observada com maior freqüência no decorrer do experimento, concorda com as afirmações de BROWN $\boldsymbol{e t}$ al. (1985), BARSANTI (1988) e CHEW \& DIBARTOLA (1992) que a insuficiência renal aguda não-oligúrica é uma característica observada freqüentemente na nefrotoxicidade induzida experimentalmente por gentamicina em cães, mas podendo ocorrer a oligúria durante o período de administração da gentamicina. Anúria observada em um cão é explicada por CHEW \& DIBARTOLA (1992) quando citam os mecanismos que contribuem para a queda da taxa de filtração glomerular ou redução da velocidade do fluxo tubular durante a insuficiência renal aguda.

As complicações gastrointestinais caracterizadas por vômito e diarréia sanguinolenta também observadas neste experimento, são considerados os sinais urêmicos mais importantes na insuficiência renal. CHEW \& DIBARTOLA(1992) supõe que o vômito se deva à estimulação da zona de disparo quimiorreceptor na medula, por uma toxina urêmica ainda não identificada. A diarréia sanguinolenta fica explicada pela principal anormalidade hemostática na uremia que é desencadeada por um defeito qualitativo no funcionamento das plaquetas.

As complicações neurológicas como hiperexcitabilidade, tremores e convulsões observadas em um cão do experimento, é citada por CHEW \& DIBARTOLA (1992), como sendo encefalopatia urêmica que geralmente não ocorre até que a taxa de filtração glomerular esteja reduzida a aproximadamente $10 \%$ do normal. Várias hipóteses são consideradas na tentativa de explicação deste fato, CHEW \& DIBARTOLA (1992) consideraram a possibilidade de que distúrbios no conteúdo de aminoácidos do plasma e líquido cefalorraquidiano, causados pelas toxinas urêmicas, poderiam levar à alteração dos neurotransmissores, contribuindo para a ocorrência de encefalopatia urêmica.

No presente estudo, a respeito da urinálise observou-se proteinúria, glicosúria, cilindrúria, hematúria e isostenúria que também foram citados por BROW et al. (1985), GRECO et al. (1985), BAYLY et al. (1986), BROWN et al. (1986), OGURA (1986) e MEALEY \& BOOTHE (1994).

Os valores da densidade urinária decresceram em todos os animais, sendo que seis deles apresentaram isostenúria, concordando com os achados de BAYLY et al (1986), BROWN et al. (1986), OGURA (1986) e GRAUER (1989), que é explicado pelo fato de que a gentamicina acumula-se nas células tubulares proximais interferindo no metabolismo celular e desencadeando nefrose tubular, como afirmam, GRECO et al. (1985), HARDY et al. (1985), BROW et al. (1986), SCHUMACHER et al. (1991), MEALEY \& BOOTHE (1994). Dessa forma o filtrado glomerular passa pelos túbulos renais e sem sofrer reabsorção é eliminado na mesma concentração do filtrado glomerular (OSBORNE \& POLZIN, 1983; 
BROBST, 1989; WILLARD $\boldsymbol{e t}$ al., 1994; MEYER $\boldsymbol{e t}$ al. (1995). A coloração da urina, sofreu variação acompanhando o decréscimo da densidade urinária, como explicado por MATOS \& MATOS (1988) e MEYER et al. (1995) quando afirmam que as amostras de urina diluída são freqüentemente incolores, pela presença reduzida de urocromos.

A proteinúria tubular associada com a administração de gentamicina, observada neste experimento e citada por vários autores, é explicada por SPANGLER $\boldsymbol{e t}$ al. (1980) e BROWN et al.. (1986), como tendo dois mecanismos que contribuem para o seu aparecimento: 1)B2-microglobulin, lisozima, albumina e outras proteínas de baixo peso molecular normalmente não são reabsorvidas a nível de túbulos proximais, desencadeando uma pequena proteinúria; 2) Certas enzimas lissosomais não são filtradas pela membrana glomerular, mas aparecem no lúmen tubular em conseqüência à lesão das células tubulares produzida pela gentamicina.

A glicosúria observada em seis cães (54\%) deste experimento, segundo BROWN et al. (1985) deve-se a "overdose" de gentamicina que normalmente ocorre em casos experimentais. BROWN et al. (1986), BROBST (1989) e MEYER $\boldsymbol{e}$ al . (1995), afirmam que a glicosúria confirma a diminuição da capacidade de rebsorção tubular de glicose.

$\mathrm{Na}$ sedimentoscopia observou-se a presença de células tubulares renais e cilindros granulosos que também é referida por BROWN et al. (1985), BROWN et al. (1986), OGURA (1986) e MEALEY \& BOOTHE (1994), sendo que esta foi evidenciada em $56 \%$ dos animais na fase final deste experimento, concordando com GRECO et al. (1985) e SCHUMACHER $\boldsymbol{e t}$ al. (1991) confirmando o que foi proposto anteriormente, de que a cilindrúria não é o método mais eficaz para detectar lesão tubular renal induzida por gentamicina. CHEW \& DIBARTOLA (1992) afirmam que as células tubulares renais e cilindros originam-se de restos celulares, a medida que desenvolve-se uma lesão celular progressiva. Os achados de piúria e bacteriúria citados nesta pesquisa foram atribuídos 'a infecção do trato urinário, baseados nas afirmações de POLZIN et al. (1992), quando chamam a atenção que, a formação de urina não concentrada, a diminuição do fluxo urinário causado pela oligúria ou até mesmo anúria, e a uremia, são fatores pré-disponentes para a infecção do trato urinário. Ademais, a uremia se caracteriza pela redução da imunocompetência.

A atividade da enzima gama glutamil transpeptidase urinária apresentou elevação a partir de 24 horas de aplicação da gentamicina. Estes achados também foram citados em outras espécies por BAYLY et al. (1986), SHAW (1976 e GARRY et al. (1990). Estas afirmações podem ser explicadas pela própria farmacocinética da gentamicina.

No presente estudo notou-se que a elevação da atividade da gama glutamil transpeptidase urinária precedeu o aparecimento de proteinúria e glicosúria concordando com as afirmações de BRAUN $\boldsymbol{e t}$ al. (1983), GRECO et al. (1985), BAYLY et al. (1986), BRAUN et al. (1987) e POLZIN et al. (1992) e RUDOLPH \& CORVALAN (1992), quando citam que as enzimas urinárias foram consideradas como marcadores precoces de nefrotoxicidade. Em adição, o aumento da gama glutamil transpeptidase urinária foi significativo durante todo o curso do estudo em discussão (14 dias), indicando que esta enzima mantem-se elevada na presença de lesão tubular renal, como também afirmam GRECO $\boldsymbol{e} \boldsymbol{t} \boldsymbol{a l}$. (1985) e HEIENE et al. (1991).

O aumento da concentração sérica de uréia e creatinina, também citados por RAISBECK $\boldsymbol{e t} \boldsymbol{a l}$. (1983), BROWN et al. (1985), BROW et al. (1986), FRAZIER et al. (1986), OGURA (1986), FRAZIER et al. (1988), GRAUER (1989) e SCHUMACHER et al. (1991) podem ser explicados pela nefrose tubular aguda produzida com a administração de gentamicina.

\section{CONCLUSÕES}

A mensuração da atividade da enzima urinária gama glutamil transpeptidase é um sensível indicador de lesão tubular renal, induzida por gentamicina, possibilitando o diagnóstico precoce de lesão tubular renal, juntamente com a urinálise; a determinação da concentração sérica de uréia e creatinina são de pouco ou nenhum valor na detecção de doença renal tubular precoce.

\section{FONTES DE AQUISIÇÃO}

a - Gentamicina 280mg. Royton Química Farmacêutica Ltda. Av. Dr. Cardoso de Melo 1318. São Paulo, SP.

b - URÉIA CELM. Cia Equipadora de Laboratórios Modernos. São Paulo, SP. CREATININA BIOCLIN. Químico Básica Ltda. Belo Horizonte, MG.

c - Milton Roy Company/Analytical Productos Division. Rochester, NY.

d - RAPIGNOST TOTAL SCREEN - Behring. Marburg, Germany. e - Refratômetro Modelo 10406. Instrument Division. USA.

\section{AGRADECIMENTOS}

Os autores agradecem ao Prof. José Henrique Souza da Silva e Prof. João Francisco de Oliveira pela realização da 
Análise Estatística, e ao Departamento de Fisiologia pelo uso de seu laboratório de pesquisa.

\section{REFERÊNCIAS BIBLIOGRÁFICAS}

BARSANTI, J.A. Distúrbios urinários. In: KIRK, R.W Atualização terapêutica veterinária. São Paulo: Manole, 1988 , v. 2, cap. 13 , p. 1395-1529.

BAYLY, W.M.J, BROBST, R.S., ELFERS, R.S. et al. Serum and urinary biochemistry and enzyme changes in ponies with acute renal failure. Cornell Veterinary, v. 76, p. 306-316, 1986

BEHREND, E.N., GRAUER, G.F., GRECO, D.S. et al. Effects of dietary protein conditioning on gentamicin pharmacokinetics in dogs. Journal Veterinary Phramacology Therapeutics, v. 17 , p. $259-264,1994$.

BRAUN, J.P., BENARD, P., BURGAT, V. et al. Gamma glutamyl transferase in domestic animals. Veterinary Research Communications, v. 6, p. 77-90, 1983.

BRAUN, J.P., SIEST, G., RICO, A.G. Uses of gama glutamyltransferase in experimental toxicology. Advances in Veterinary Science and Comparative Medicine, v. 31, p. 151-173, 1987.

BROBST, D. Urinalysis and associated laboratory procedures. Veterinary Clinics of North America: Small Animal Practice, v. 19, n. 5, p. 929-949, 1989

BROWN, S.A., BARSANTI, J.A., CROWELL, W.A. Gentamicinassociated acute renal failure in the dog. Journal of the American Veterinary Medical Association, v. 186, n. 7, p. 686-690, 1985.

BROWN, S.A., RAKICH, P.M., BARSANTI, J.A. et al. Fancon syndrome and acute renal failure associated with gentamicin therapy in a dog. Journal of the American Animal Hospital Association, v. 22, p. 635-640, 1986

CHEW, D.J., DIBARTOLA, S.P. Diagnóstico e fisiopatologia da moléstia renal. In: ETTINGER S.J. Tratado de medicina interna veterinária. São Paulo: Manole, 1992, v. 4. cap. 107. p. 1975-2046.

COLES, E.H. Patologia clínica veterinária. 3. ed. São Paulo: Manole, 1984. 566 p.

DE SCHEPPER, J., DE COCK, I., CAPIAU, E. Urinary gama glutamil transferese and the degree of renal dysfuhction in 75 bitches with pyonetra. Research in Veterinary Science, v. 46, p. 396-400, 1989.

FINCO, D.R. Kidney function. In: KANEKO, J.J. Clinical biochemitry of domestic animals. Davis: Academic, 1989 , cap. 18 . p. $496-542$

FONTES, E.M., PESSOA, J.F.S., SILVA, A.J. et al. Interpretação estatística de alguns parâmetros do exame laboratorial de urina em canídeos. Anais da Escola Superior de Medicina Veterinária de Lisboa, v. 22, p. 71-91, 1980

FRAZIER, D.L., ANCOIN, D.P., RIVIERE, J.E. Gentamicin pharmacokinetics and nephrotoxicity in naturally acquired and experimentally induced disease in dogs. Journal of the American Veterinary Medical Association, v. 192, n. 1, p. 57-63, 1988.

FRAZIER, D.L., DIX, L.P., BOWMAN, K.F., et al. Increased gentamicin nephrotoxicity in normal and diseased dogs administered identical serum drug concentration profiles: increased sensitivity in subclinical renal dysfunction. The Journal of Pharmacology and Experimental Therapeutics, v. 239, n. 3, p. 946-951, 1986.

GARRY, F., CHEW, D.J., HOFFSIS, G.F. Enzymuria as and index of renal damage in sheep with induced aminoglycoside nephrotoxicosis. American Journal of Veterinary Research, v. 51, n. 3 , p. $428-432,1990$

GOSSETT, K.A., TURNWALD, G.H., KEARNEY, M.T. $\boldsymbol{e}$ t al Evaluation of gamma glutamyl transpeptidase-to-creatinine ratio from spot samples of urine supernatant, as an indicator of urinary enzyme excretion in dogs. American Journal of Veterinary Research, v. 48, n. 3, p. 455-457, 1987.

GRAUER, G.F. Toxicant-induced acute renal failure. In: KIRK, R.W Current veterinary therapy X. Philadelphia: Saunders, 1989, v. 11, p. $126-130$.

GRECO, D.S., TURNWALD, G.H., ADAMS, R. et al. Urinary gama glutamil transpeptidase activity in dogs with gentamicininduced nephrotoxicity. American Journal of Veterinary Research, v. 46, n. 11, p. 2332-2335, 1985.

HARDY, M.L., RUEI-CHING HSU, SHORT, C.R. The nephrotoxic potential of gentamicin in the cat: enzymuria and alterations in urine concentrating capability. Journal Veterinary Phramacology Therapeutics, v. 8, p. 382-392, 1985.

HEIENE, R., BIEWENGA, W.J., KOEMAN, J.P. Urinary alkaline phosphatase and gama glutamyl transferase as indicators of acute renal damage in dogs. Journal of Small Animal Practice, v. 32 , p. $521-524,1991$.

MATOS, M.S., MATOS, P.F. Laboratório clínico médico veterinário. 2. ed. Rio e Janeiro: Atheneu, 1988. 238 p.

MEALEY, K.L., BOOTHE, D.M. Nephrotoxicosis associated with topical administration of gentamicin in a cat. Journal of the American Veterinary Medical Association, v. 204, n. 12, p. 1919-1921, 1994

MEYER, D.J., COLES, E.H., RICH, L.J. Medicina de laboratório veterinária. São Paulo: Roca, 1995. 308 p.

OGURA, T. Assay of urinary enzymes in the dog and cat. Japan Journal of Veterinary Research, v. 34, p. 149, 1986.

OSBORNE, C.A., POLZIN, D.J. Azotemia: a review of whats new part I. Definition of terms and concepts. The Compendium on Continuing Education, v. 5, n. 6, p. 497-508, 1983.

POLZIN, D., OSBORNE, C., O'BRIENT, T. Moléstia dos rins e ureteres. In: ETTINGER, S.J. Tratado de medicina interna veterinária. São Paulo: Manole, 1992, v. 4. cap. 108. p. 20472138 .

PRICE, R.G. Urinary enzymes, nephrotoxicity and renal disease. Toxicology, v. 23, p. 99-134, 1982 
RAISBECK, M.F., HEWITT, W.R., McINTYRE, W.B. Fatal nephrotoxicosis associated with furosemide and gentamicin therapy in a dog. Journal of the American Veterinary Medical Association, v. 183, n. 8, p. 892-895, 1983.

RUDOLPH. W.G., CORVALAN, E.O. Urinary and serum gamma glutamyl transpeptidase in relation to urinary $\mathrm{pH}$ and proteinuria in healthy thoroughbred horses in training. Equine Veterinary Journal, v. 24, n. 4, p. 316-317, 1992.

SALGÓ, L., SZABÓ, A. Gamma glutamyl transpeptidase activity in human urine. Clinical Chimica Acta, v. 126, n. 1, p. 9-16, 1982.

SCHUMACHER, J., WILSON, R.C., SPANO, J.S. et al. Effect of diet on gentamicin-induced nephrotoxicosis in horses. American Journal of Veterinary Research, v. 52, n. 8, p. 1274-1278, 1991.

SHAW, F.D. The effect of mercuric chloride intoxication on urinary gama glutamyl transpeptidase excretion in the sheep. Research in Veterinary Science, v. 20, p. 226-228, 1976.

SPANGLER, W.L., ADELMAN, R.D. CONZELMAN, G.M. et al. Gentamicin nephrotoxicity in the dog: sequential light and electron microscopy. Veterinary Phatology, v. 17, p. 206-217, 1980 .

STROO, W.E., HOOK, J.B. Enzymes of renal origin in urine as indicators of nephrotoxicity. Toxicology and Applied Pharmacology, v. 39, p. 423-434, 1977.

WILLARD, M.D., TVEDTEN, H., TURNWALD, G.H. Small animal clinical diagnosis by laboratory methods. 2. ed. Philadelphia: Saunders. 1994. 377 p. 